\title{
Risk and Risk Factors for Postpartum Type 2 Diabetes Mellitus in Women with Gestational Diabetes: A Korean Nationwide Cohort Study
}

\author{
Mi Jin Choi ${ }^{1}$, Jimi Choi ${ }^{2}$, Chae Weon Chung ${ }^{3}$ \\ ${ }^{1}$ Department of Nursing, Chodang University, Muan; ${ }^{2}$ Division of Endocrinology and Metabolism, Department of Internal \\ Medicine, Korea University College of Medicine; ${ }^{3}$ College of Nursing, Seoul National University, Seoul, Korea
}

Background: There are differences in risk and risk factor findings of postpartum type 2 diabetes mellitus (T2DM) after gestational diabetes depending on study design and subjects of previous studies. This study aimed to assess these risk and risk factors more accurately through a population-based study to provide basic data for prevention strategies.

Methods: This open retrospective cohort included data of 419,101 women with gestational diabetes and matched 1,228,802 control women who delivered between 2004 and 2016 from the South Korea National Health Information Database of the National Health Insurance Service. Following 14 (median 5.9) years of follow-up, the incidence and hazard ratio (HR) of postpartum T2DM were evaluated using Kaplan-Meier curves and Cox proportional regression models.

Results: The incidence and HR of postpartum T2DM in women with gestational diabetes (compared to women without gestational diabetes) after the 14-year follow-up was $21.3 \%$ and 2.78 (95\% confidence interval [CI], 2.74 to 2.82), respectively. Comorbid obesity (body mass index $[\mathrm{BMI}] \geq 25 \mathrm{~kg} / \mathrm{m}^{2}$ ) increased postpartum T2DM risk 7.59 times (95\% CI, 7.33 to 7.86 ). Significant risk factors for postpartum T2DM were fasting glucose level, BMI, age, family history of diabetes, hypertension, and insulin use during pregnancy.

Conclusion: This population-based study showed higher postpartum T2DM risk in women with gestational diabetes than in those without, which was further increased by comorbid obesity. BMI and fasting glucose level were important postpartum risk factors. The management of obesity and glycemic control may be important strategies to prevent the incidence of diabetes after delivery.

Keywords: Diabetes, gestational; Diabetes mellitus, type 2; Postpartum period; Body mass index; Glycemic control; Cohort studies

\section{INTRODUCTION}

Gestational diabetes, a risk factor for postpartum type 2 diabetes mellitus (T2DM), threatens women's health [1-3]. The prevalence of obesity, a known risk factor for gestational diabetes, has increased, and a further increase in the incidence of gesta-
Received: 23 September 2021, Revised: 22 December 2021,

Accepted: 18 January 2022

Corresponding author: Jimi Choi

Division of Endocrinology and Metabolism, Department of Internal Medicine, Korea University Anam Hospital, Korea University College of Medicine,

73 Goryeodae-ro, Seongbuk-gu, Seoul 02841, Korea

Tel: +82-2-920-5767, Fax: +82-2-953-9355, E-mail: jjimchoi@gmail.com
Copyright $\odot 2022$ Korean Endocrine Society

This is an Open Access article distributed under the terms of the Creative Commons Attribution Non-Commercial License (https://creativecommons.org/ licenses/by-nc/4.0/) which permits unrestricted non-commercial use, distribution, and reproduction in any medium, provided the original work is properly cited. 
tional diabetes and postpartum T2DM is expected [4-6]. The incidence of diabetes in Asians, especially in age groups younger than 40 years, has escalated $[4,7,8]$, and the onset of diabetes at a young age increases the chances of long-term complications and decreased quality of life [9]. Therefore, increased interest in women with gestational diabetes who have a high risk of diabetes is essential to prevent diabetes, particularly in young women.

Previous studies have reported postpartum T2DM incidence rates of $2.6 \%$ to $70 \%$ in women with gestational diabetes [1012]. The prevalence of gestational diabetes and incidence of diabetes can differ by race and geographic region, and Asian women are known to have a higher risk of developing postpartum T2DM $[1,13,14]$. In a recent meta-analysis of T2DM after gestational diabetes, the highest incidence rate (45.96/1,000 personyears) was in Asian women, whereas the incidence rates in four Korean studies ranged from 10.51 to 78.33 per 1,000 personyears [1]. Additionally, the postpartum T2DM incidence rate differs according to the follow-up period, with a relatively higher risk in studies with longer observation periods [3]. Hospitalbased cohort studies are limited because of biased recruitment, limited subjects, and drop-outs during follow-up. These may overestimate the incidence of postpartum T2DM since women with pregestational diabetes may be included $[11,15,16]$. Therefore, it is necessary to conduct a population-based study with a large representative sample of women with gestational diabetes, excluding pregestational diabetes and a long observation period.

Postpartum screening tests and healthy lifestyles are recommended to prevent and manage postpartum T2DM in women with gestational diabetes [17-19]. However, the recommended performance level of health behaviors is often not achieved [20]. The key obstacle for why women with gestational diabetes have suboptimal health behavior performance is because they do not perceive themselves to be at an increased risk of postpartum T2DM [21]. Therefore, identifying individualized risk levels according to individual risk factors is an important first step in the prevention and management of T2DM. When identifying risk factors, the timing of diabetes onset is essential. The risk and risk factors differ in the early and late (greater than 1 year follow-up) postpartum periods [15,22], and defects in beta-cell function, partly explained by genetic predisposition, are more remarkable in early converters [15]. Risk factors of postpartum T2DM across the perinatal period include pre-pregnancy obesity, gestational diabetes diagnostic test results during pregnancy, postpartum metabolism tests results, and obesity [22-27]. Given the potential for prevention strategy and usefulness of postpartum counseling for women with gestational diabetes, it is neces- sary to focus on late-onset postpartum T2DM and modifiable factors in the postpartum period. Therefore, more comprehensive risk factor assessments, including postpartum fasting glucose level, body mass index (BMI), healthy behaviors, type of breastfeeding, as well as known pre-pregnancy and pregnancy risk factors of T2DM 1-year postpartum, are needed.

In this study, the long-term incidence of postpartum T2DM in postpartum women, including those with gestational diabetes, was assessed using data from the National Health Information Database (NHID) of the National Health Insurance Service (NHIS), South Korea. This study aimed to assess the incidence of diabetes according to the presence of gestational diabetes and comorbid obesity and to identify risk factors, including postpartum factors, for the incidence of T2DM 1 year after delivery.

\section{METHODS}

\section{Data source}

This nationwide population-based cohort study used data from the NHIS-NHID, South Korea. The NHIS is the single insurer of the nation and covers the entire population of the country $(52,922,000$ persons as of September 2021; health insurance subscribers, 51,398,000 [97.1\%]; and medical aid beneficiaries, $1,524,000$ [2.9\%]) [28]. The NHIS manages insurance eligibility and insurance contributions, receives claims of medical treatments from health care institutions, and pays medical expenses $[29,30]$. The data systematically collected through these processes, which are stored in the NHID, include information on the medical service usage (including disease and drug codes) from the medical treatment and prescription databases, bio-clinical measurements and behavioral health information from the health screening database, and socio-demographics from the eligibility database (Supplemental Fig. S1). Moreover, breastfeeding information was utilized from the health screening database of infants, which was identified by the mother-child identical health insurance number and the same index delivery year of mother and birth year of the child. For research purposes, the NHID data were anonymized according to strict confidentiality guidelines and regulations by the NHIS, and details of the utilization and validity of the NHID are described elsewhere [29,30]. This study was granted an exemption from ethics approval by the Institutional Review Board (IRB) of Chodang University (2018-06) and approved by the NHIS review board (NHIS-2019-1-044), and the requirement of informed consent was waived by the IRB due to the use of de-identified secondary data. 


\section{Study subjects}

The study subjects were pregnant women with and without gestational diabetes mellitus who were identified using delivery claim codes (the Korean Standard Classification of Diseases 7th Revision reflects the International Statistical Classification of Diseases and Related Health Problems 10th Revision [ICD-10] Z32.1, Z33, Z34, Z35, and O00-99) between 2004 and 2016 in the NHIS-NHID. Women with gestational diabetes were identified as having gestational diabetes mellitus (ICD-10 O24.4 code) during the second and third trimesters of pregnancy. The American Diabetes Association's gestational diabetes definition (diabetes diagnosed in the second or third trimester of pregnancy that is not clearly overt diabetes) [17] was applied in this study as part of an effort to rule out pregestational diabetes. We strictly excluded those with pre-existing diabetes by excluding those with diabetes ICD-10 codes E10-E14 and O24 before and during the first trimester of pregnancy and those with pregestational or unspecified gestational diabetes with ICD-10 codes O24.0, O24.1, O24.2, O24.3, and 24.9, at any time. Women with a history of gestational diabetes in any delivery were included in the gestational diabetes group, and the index date was defined as the first delivery date when gestational diabetes was identified. The control group included subjects who had not been diagnosed with gestational diabetes in all pregnancies. This study was an open cohort study with a long enrollment period and some subjects had several deliveries during the study period. There were differences in the prevalence of gestational diabetes and the incidence of postpartum T2DM according to the year of delivery and age (Supplemental Fig. S2: results of further analysis in this dataset showing the difference in risk of incidence of postpartum T2DM according to the year of delivery and advanced maternal age) [10,31], and advanced maternal age and multiparty were associated with incidence of postpartum T2DM in women with gestational diabetes (advanced maternal age: relative ratio [RR], 1.20; 95\% confidence interval [CI], 1.09 to 1.34 ; and multiparity: RR, 1.23 ; $95 \% \mathrm{CI}, 1.01$ to 1.50) [22]. Therefore, matching was performed to establish a comparable control group. Women in the gestational diabetes group were randomly matched with two to five controls by index year, age ( \pm 3 years), and order of index delivery (first, second, and $\geq$ third delivery). To determine the risk factors for diabetes incidence after delivery in the gestational diabetes group, we excluded subjects who were diagnosed with diabetes within 1 year after index delivery, or who had no data related to the infant or health examination. This is because we focused on the incidence of diabetes in the late postpartum period (1 year after delivery) and the factors after delivery.

\section{Outcomes and covariates}

Postpartum T2DM occurring at least 6 weeks after delivery was defined as one of the following: two or more claims with T2DM code (ICD-10 E11-14), claims for any insulin or oral hypoglycemic agents, or fasting glucose $\geq 126 \mathrm{mg} / \mathrm{dL}[32,33]$. Covariates included age (years at the end day of index year); type of insurance (self-employed, employee, and Medicaid); employment ("yes" and "no"); hypertension (ICD-10 I10-I15); cardiovascular disease (ICD-10 I20-I25, I60-I69); pregnancy-induced hypertensive disorders (ICD-10 O13-O15); multiple births (ICD-10 Z37.2-Z37.7); family history of diabetes mellitus (parents and siblings; "yes" and "no"); physical activity $(0,1-4$, and $\geq 5$ times/week; sum of the number of exercises per week [a sweaty exercise, 20, 30, and 30 minutes of vigorous, moderate, and walking exercise, respectively]); smoking ("never," "ever," and "current"); alcohol consumption ("no," Saverage 1 glass/ day, and >average 1 glass/day), BMI $\left(\mathrm{kg} / \mathrm{m}^{2}\right)$; fasting glucose $(\mathrm{mg} / \mathrm{dL})$; systolic blood pressure $(\mathrm{mm} \mathrm{Hg})$; total cholesterol (mg/dL); and high-density lipoprotein cholesterol (HDL-C, mg/ $\mathrm{dL})$. For risk factor analysis, some variables were added and categorized based on their clinical significance: age $(<30,30$ $34,35-39$, and $\geq 40$ years); history of insulin treatment (active ingredient code 170130BIJ and 29 other codes); waist circumference $(<77,77-84.9$, and $\geq 85 \mathrm{~cm})$; BMI $(<23,23-24.9,25-$ 29.9 , and $\left.\geq 30 \mathrm{~kg} / \mathrm{m}^{2}\right)$; fasting glucose $(<100,100-109.9$, and $\geq 110 \mathrm{mg} / \mathrm{dL}$ ); systolic blood pressure $(<140$ and $\geq 140 \mathrm{~mm}$ $\mathrm{Hg})$; HDL-C ( $<35,35-49.9$, and $\geq 50 \mathrm{mg} / \mathrm{dL})$; and type of feeding (exclusive breastfeeding, mixed feeding, and formula feeding).

\section{Statistical analysis}

The characteristics of women in the gestational diabetes group and matched controls are reported as means and standard deviations (SDs) for continuous variables and numbers and percentages (\%) for categorical variables. The absolute standardized mean differences (ASMDs) were calculated to compare the distribution of baseline characteristics between the two groups, and a value $>0.1$ was considered a significant difference. Statistics for the incidence of T2DM after delivery were reported as Kaplan-Meier curves and incidence rates per 1,000 person-years. A Cox proportional regression model with a robust variance estimator was used to compare the risk of T2DM between the gestational diabetes group and matched controls, and the results were reported as hazard ratios (HRs) and corresponding 95\% 
CIs. Two multivariable Cox proportional regression models were performed according to the adjusted covariates. Model 1 included age, type of insurance, employment, hypertension, cardiovascular disease, pregnancy-induced hypertensive disorders, and multiple births as covariates. Model 2 included family history of diabetes mellitus, physical activity, smoking, alcohol consumption, BMI, fasting glucose, systolic blood pressure, and total cholesterol as covariates in addition to those in the previous model. By stratifying according to obesity category (BMI $\geq 25$ and $<25 \mathrm{~kg} / \mathrm{m}^{2}$ ), sub-group analysis was performed to compare the risk of T2DM between the gestational diabetes group and matched controls. The multivariable Cox proportional regression model with or without stepwise selection was performed to identify the risk factors for 1 year postpartum T2DM in the gestational diabetes group. SAS Enterprise Guide software version 7.1 (SAS Institute, Cary, NC, USA) and R version 4.0.1 (R Foundation for Statistical Computing, Vienna, Austria) were used to perform the statistical analyses. Statistical significance was defined as a two-sided $P$ value $<0.05$.

\section{RESULTS}

\section{Study subjects}

From January 1, 2004, to December 31, 2016, a total of $5,628,882$ deliveries by $3,763,143$ women were confirmed in South Korea. Of these, 419,101 women with gestational diabetes were included in the gestational diabetes group and 1,228,802 women without gestational diabetes in the control group, with a total of 1,647,903 subjects in the cohort (Fig. 1). The mean age of subjects in gestational diabetes and control groups was $32.4 \pm$ 3.9 and $32.1 \pm 3.9$ years, respectively. The BMI $\left(21.5 \pm 3.2 \mathrm{~kg} / \mathrm{m}^{2}\right.$ vs. $21.0 \pm 2.8 \mathrm{~kg} / \mathrm{m}^{2}$; ASMD, 0.146) and fasting glucose level $(87.6 \pm 12.1 \mathrm{mg} / \mathrm{dL}$ vs. $85.8 \pm 10.5 \mathrm{mg} / \mathrm{dL}$; ASMD, 0.156) were slightly higher in the gestational diabetes group than in the controls (Table 1). Results of additional analysis for changes in fasting glucose values during the follow-up period were presented in Supplemental Table S1. The longest follow-up period was 14 years (median, 5.9; interquartile range, 3.5 to 8.4). Overall, 686 $(0.2 \%)$ and $3,436(0.8 \%)$ subjects in the gestational diabetes

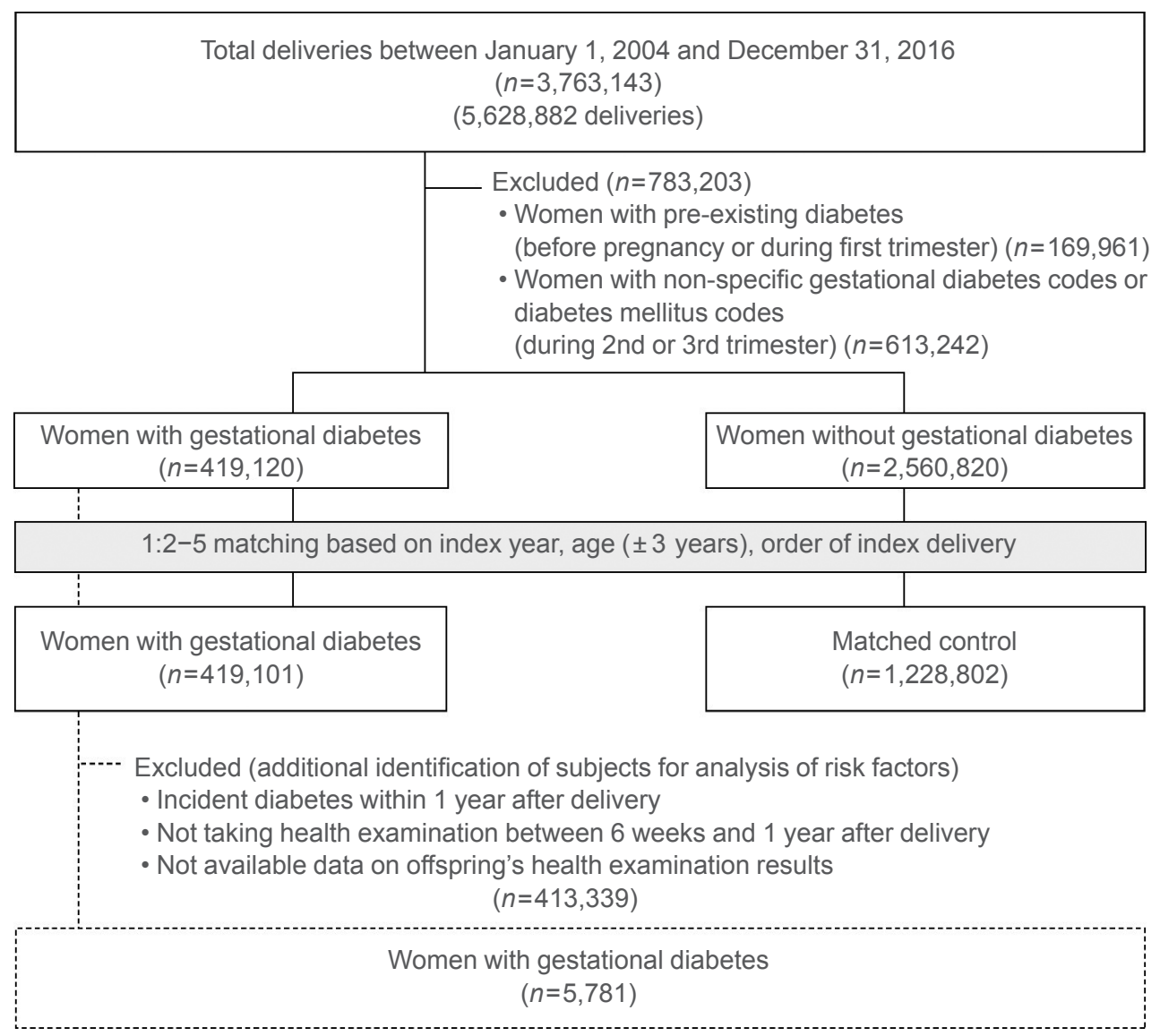

Fig. 1. Study subjects were identified for the analysis of risk of and risk factors for incident type 2 diabetes mellitus after delivery. 


\begin{tabular}{|c|c|c|c|}
\hline Characteristic & $\begin{array}{c}\text { Control } \\
(n=1,228,802)\end{array}$ & $\begin{array}{l}\text { Gestational diabetes group } \\
\qquad(n=419,101)\end{array}$ & $\mathrm{ASMD}^{\mathrm{a}}$ \\
\hline Age, yr & $32.1 \pm 3.9$ & $32.4 \pm 3.9$ & 0.069 \\
\hline Order of index delivery & & & 0.056 \\
\hline $1 \mathrm{st}$ & $848,401(69.0)$ & $279,520(66.7)$ & \\
\hline 2 nd & $333,029(27.1)$ & $119,166(28.4)$ & \\
\hline$\geq 3$ rd & $47,372(3.9)$ & $20,415(4.9)$ & \\
\hline Enrollment type of insurance & & & 0.151 \\
\hline Self-employed & $321,506(26.2)$ & $99,388(23.7)$ & \\
\hline Employee & $900,416(73.3)$ & $317,823(75.8)$ & \\
\hline Medicaid & $6,880(0.6)$ & $1,890(0.5)$ & \\
\hline Income classification & $11(7-15)$ & $12(8-15)$ & 0.030 \\
\hline Employment & $438,108(35.7)$ & $157,891(37.7)$ & 0.042 \\
\hline Hypertension & $14,690(1.2)$ & $7,448(1.8)$ & 0.048 \\
\hline Cardiovascular diseases & $8,730(0.7)$ & $3,409(0.8)$ & 0.012 \\
\hline PIHD & $6,842(0.6)$ & $3,955(0.9)$ & 0.045 \\
\hline Multiple birth & $525(0.04)$ & $272(0.06)$ & 0.010 \\
\hline Body mass index, $\mathrm{kg} / \mathrm{m}^{2}$ & $21.0 \pm 2.8$ & $21.5 \pm 3.2$ & 0.146 \\
\hline Waist circumference, $\mathrm{cm}$ & $71.2 \pm 8.6$ & $72.1 \pm 9.1$ & 0.099 \\
\hline Family history of diabetes mellitus & $255,456(42.8)$ & $106,579(47.4)$ & 0.092 \\
\hline Physical activity, times/week & & & 0.076 \\
\hline 0 & $406,891(63.2)$ & $146,211(60.1)$ & \\
\hline $1-4$ & $201,040(31.3)$ & $80,766(33.2)$ & \\
\hline$\geq 5$ & $35,564(5.5)$ & $16,478(6.8)$ & \\
\hline Ever smoker & $55,580(8.7)$ & $24,695(10.2)$ & 0.052 \\
\hline Alcohol consumption, unit/day & & & 0.103 \\
\hline No & $387,941(64.1)$ & $143,039(62.0)$ & \\
\hline$\leq$ average 1 glass/day & $99,087(16.4)$ & $32,415(14.1)$ & \\
\hline >average 1 glass/day & $118,197(19.5)$ & $55,179(23.9)$ & \\
\hline Fasting glucose, $\mathrm{mg} / \mathrm{dL}$ & $85.8 \pm 10.5$ & $87.6 \pm 12.1$ & 0.156 \\
\hline Systolic blood pressure, $\mathrm{mm} \mathrm{Hg}$ & $110.1 \pm 11.0$ & $110.8 \pm 11.4$ & 0.066 \\
\hline Diastolic blood pressure, $\mathrm{mm} \mathrm{Hg}$ & $69.1 \pm 8.3$ & $69.5 \pm 8.5$ & 0.051 \\
\hline Triglycerides, mg/dL & $92.4 \pm 67.8$ & $97.5 \pm 72.8$ & 0.072 \\
\hline $\mathrm{HDL}-\mathrm{C}, \mathrm{mg} / \mathrm{dL}$ & $65.2 \pm 14.7$ & $64.4 \pm 14.8$ & 0.054 \\
\hline Total cholesterol, mg/dL & $180.2 \pm 35.9$ & $183.0 \pm 35.9$ & 0.078 \\
\hline
\end{tabular}

group and 3,082 (0.3\%) and 18,236 (1.5\%) in the control group were censored due to death and exclusion from the list of eligible health insurance subscribers, respectively.

There were 5,781 women with gestational diabetes included in the risk factor analysis for 1 year postpartum T2DM (Fig. 1, Supplemental Table S2). During the follow-up period of a maximum of 8.5 years (median, 3.9), T2DM occurred in 302 of 5,781 women (14.1 cases per 1,000 person-year). 
Table 2. Risk of Type 2 Diabetes Mellitus after Delivery among Women with or without Gestational Diabetes

\begin{tabular}{|c|c|c|c|c|c|c|c|c|c|c|}
\hline \multirow[b]{2}{*}{ Variable } & \multicolumn{3}{|c|}{ Total subjects } & \multicolumn{3}{|c|}{ Body mass index $\geq 25 \mathrm{~kg} / \mathrm{m}^{2}$} & \multicolumn{3}{|c|}{ Body mass index $<25 \mathrm{~kg} / \mathrm{m}^{2}$} & \multirow{2}{*}{$\begin{array}{l}P \text { value for } \\
\text { interaction }\end{array}$} \\
\hline & Control & $\begin{array}{c}\text { Gestational } \\
\text { diabetes group }\end{array}$ & $P$ value & Control & $\begin{array}{c}\text { Gestational } \\
\text { diabetes group }\end{array}$ & $P$ value & Control & $\begin{array}{c}\text { Gestational } \\
\text { diabetes group }\end{array}$ & $P$ value & \\
\hline $\begin{array}{l}\text { Number of } \\
\text { events }\end{array}$ & 41,966 & 30,383 & & 3,405 & 4,440 & & 13,717 & 9,516 & & \\
\hline $\begin{array}{l}\text { Incidence rate, } \\
/ 1,000 \mathrm{PY}\end{array}$ & 5.2 & 14.1 & & 10.3 & 32.7 & & 4.0 & 9.5 & & \\
\hline $\begin{array}{l}\text { Crude HR } \\
(95 \% \mathrm{CI})\end{array}$ & 1 (reference) & $2.81(2.77-2.85)$ & $<0.001$ & 1 (reference) & $3.26(3.12-3.41)$ & $<0.001$ & 1 (reference) & $2.43(2.37-2.50)$ & $<0.001$ & $<0.001$ \\
\hline $\begin{array}{l}\text { Adjusted HR }{ }^{\mathrm{a}} \\
(95 \% \mathrm{CI})\end{array}$ & 1 (reference) & $2.78(2.74-2.82)$ & $<0.001$ & 1 (reference) & $3.21(3.07-3.36)$ & $<0.001$ & 1 (reference) & $2.40(2.34-2.47)$ & $<0.001$ & $<0.001$ \\
\hline $\begin{array}{l}\text { Adjusted } \mathrm{HR}^{\mathrm{b}} \\
(95 \% \mathrm{CI})\end{array}$ & 1 (reference) & $2.59(2.52-2.65)$ & $<0.001$ & 1 (reference) & $2.84(2.70-2.98)$ & $<0.001$ & 1 (reference) & $2.31(2.24-2.37)$ & $<0.001$ & $<0.001$ \\
\hline
\end{tabular}

PY, person-years; HR, hazard ratio; CI, confidence interval.

${ }^{a}$ Adjustment variables for total subjects: age, enrollment type of insurance, employment, hypertension, cardiovascular disease, pregnancy-induced hypertensive disorders, multiple births; ${ }^{b}$ Adjustment variables for subjects with health check-up data: age, enrollment type of insurance, income classification for insurance premiums, employment, hypertension, cardiovascular disease, pregnancy-induced hypertensive disorders, multiple births, family history of diabetes mellitus, physical activity, smoking, alcohol consumption, body mass index, fasting glucose, systolic blood pressure, and total cholesterol.

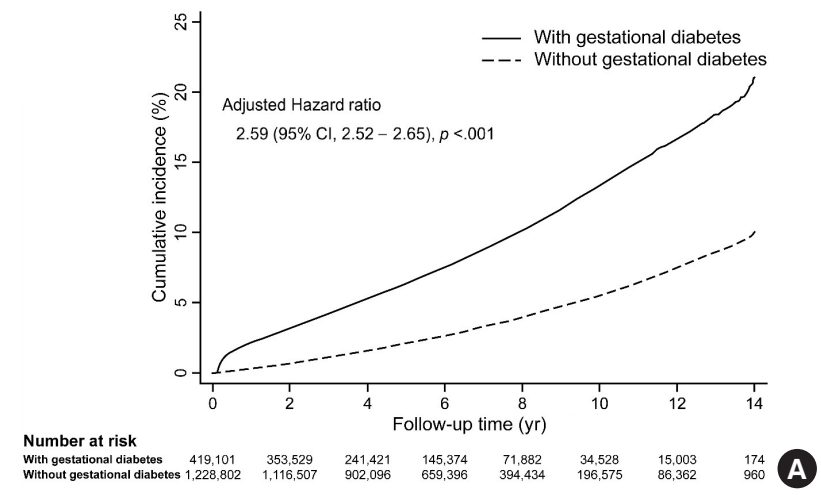

Fig. 2. Cumulative incidence rate of type 2 diabetes mellitus after delivery was evaluated by Kaplan-Meier curves according to gestational diabetes (A), gestational diabetes and obesity (B). CI, confidence interval.

\section{Risk and risk factors for postpartum type 2 diabetes mellitus}

During the 14-year observation period, 30,383 of the 419,101 subjects in the gestational diabetes group and 41,966 of the $1,228,802$ subjects in the control group developed postpartum T2DM (Table 2). The incidence of T2DM in the gestational diabetes group increased rapidly during the early postpartum period, and the 1-year postpartum cumulative incidence rate was $2.2 \%$, which then increased at a constant rate thereafter (Fig. 2A). In contrast, the incidence of T2DM in the control group increased at a relatively constant rate and was less than half of that in the gestational diabetes group. The cumulative 14-year incidence rate of postpartum T2DM was $21.3 \%$ and $10.1 \%$ in gestational diabetes and control groups, respectively.

Postpartum T2DM was observed in 14.1 and 5.2 women per 1,000 person-years in gestational diabetes and control groups, respectively (Table 2). The HR of T2DM was still high at 2.78 (95\% CI, 2.74 to $2.82 ; P<0.001)$ in the gestational diabetes group after adjusting for covariates in model 1 . In addition, the HR of T2DM in the gestational diabetes group was $2.59(95 \%$ CI, 2.52 to $2.65 ; P<0.001)$ after additional covariates adjustment in model 2. 


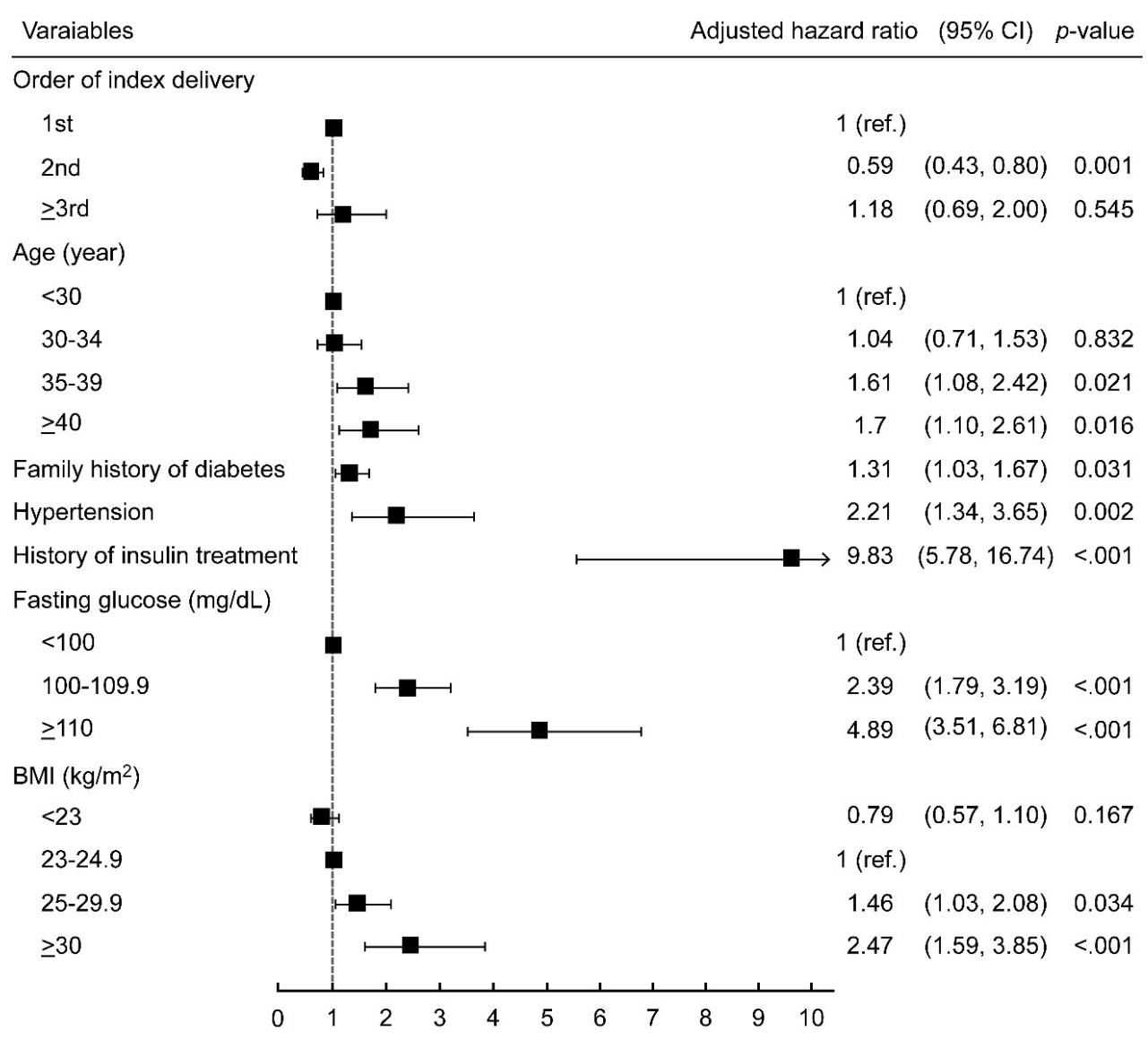

Fig. 3. A forest plot showed significant risk factors for incident type 2 diabetes mellitus 1 year after delivery among women with gestational diabetes. CI, confidence interval; BMI, body mass index.

When analyzed by the obesity group, the interaction between obesity (BMI $25 \mathrm{~kg} / \mathrm{m}^{2}$ ) and gestational diabetes was statistically significant $(P<0.001)$, and those with gestational diabetes had a higher risk of T2DM in the obese group (HR, 2.84; $95 \%$ CI, 2.70 to $2.98 ; P<0.001)$ than in the non-obese group (HR, $2.31 ; 95 \%$ CI, 2.24 to $2.37 ; P<0.01$ ) (Table 2). Those with both obesity and gestational diabetes showed a 7.59-times $(95 \% \mathrm{CI}$, 7.33 to $7.86 ; P<0.001)$ greater risk of developing postpartum T2DM compared to those without both obesity and gestational diabetes (Fig. 2B). Those with only obesity or gestational diabetes showed differences in the cumulative incidence of postpartum T2DM over time. A low incidence rate of postpartum T2DM was observed initially in those with obesity only, which increased steeply afterward. Conversely, a high incidence rate was observed in the early postpartum period in those with gestational diabetes only, which increased at a lower rate thereafter. As a result, the cumulative incidence rate, which was higher in the gestational diabetes group than in the obesity group, was reversed at 5 years, and the rate was higher in the obesity group afterward (Fig. 2B).

The significant risk factors for postpartum T2DM were BMI of $25-29.9$ and $>30 \mathrm{~kg} / \mathrm{m}^{2}$ (HR, $1.46 ; 95 \%$ CI, 1.03 to 2.08 ; $P=0.034$; and HR, 2.47 ; $95 \% \mathrm{CI}, 1.59$ to $3.85 ; P<0.001$, respectively), compared to those with BMI of $23-24.9 \mathrm{~kg} / \mathrm{m}^{2}$ (Fig. 3) and fasting glucose level of 100-109.9 and $>110 \mathrm{mg} / \mathrm{dL}$ (HR, 2.39; $95 \% \mathrm{CI}, 1.79$ to $3.19 ; P<0.001$; and HR, 4.89 ; $95 \% \mathrm{CI}$, 3.51 to $6.81 ; P<0.001$, respectively), compared to those with a fasting glucose level of $<100 \mathrm{mg} / \mathrm{dL}$. Other factors such as age (35-39 years: HR, $1.61 ; 95 \% \mathrm{CI}, 1.08$ to $2.42 ; P=0.021 ;>40$ years: HR, $1.70 ; 95 \% \mathrm{CI}, 1.10$ to $2.61 ; P=0.016$, compared to those aged $<30$ years); family history of diabetes (HR, 1.31; $95 \% \mathrm{CI}, 1.03$ to $1.67 ; P=0.031$ ); diagnosis of hypertension (HR, 2.21; $95 \% \mathrm{CI}, 1.34$ to $3.65 ; P=0.002)$; and insulin treatment during pregnancy (HR, 9.83; 95\% CI, 5.78 to $16.74 ; P<0.001$ ); significantly increased the risk of postpartum T2DM. The factors that were excluded from the stepwise selection method are shown in Supplemental Table S3. 


\section{DISCUSSION}

The cumulative incidence of postpartum T2DM in women diagnosed with gestational diabetes during a follow-up period of up to 14 years (median, 5.9 ) was $21.3 \%$. This is similar to the cumulative incidence rate of $18.9 \%$ reported by Feig et al. [10], using Canadian population-based data for up to 9 years (median, 5.4); 21,823 of 633,449 women who delivered had gestational diabetes. The cumulative incidence rate observed in our study was also higher than the $8.4 \%$ reported in an 8 -year survey study, using population-based data in Korea, of 2,962 women with gestational diabetes who delivered in 2004 [34]. In another 5 -year study of women with gestational diabetes in Korea, a $40 \%$ incidence rate of postpartum diabetes was predicted, based on the results of hospital-based prospective cohort studies [11]. This incidence rate was remarkably greater than that in our study. It was observed that the incidence rate tends to be lower in population-based studies with a long follow-up period for a large number of subjects than in hospital-based studies with a short follow-up period for a small number of subjects [1].

The incidence rate of postpartum T2DM was slightly higher in the early postpartum period and increased at a constant rate. The cumulative incidence rate in the first year after delivery was $2.2 \%$. Our finding is lower than the incidence rate of $10 \%$ to $15 \%$ observed in other Korean hospital-based cohort studies $[11,15,35,36]$, which may not have excluded pregestational diabetes. Failure to exclude pregestational diabetes can lead to an overestimation of the incidence rate in the early postpartum period. By strictly excluding pregestational diabetes in our study, a relatively lower risk of diabetes was observed.

In women with gestational diabetes, a HR of 2.59 to 2.78 was observed after adjusting for other variables. The HR observed in our study is lower than the HR of 3.5 to 4.5 reported in cohort studies on Korean women [11,16], and the relative risk ratios of 7.43 and 7.76 in meta-analysis studies, which included cohort studies on women from various regions or races [2,3]. The studies included in these meta-analyses are highly heterogeneous, such that the relative risk reported in the studies varied from 1.48 to 86.41 [2,3]; thus, generalizing the results to specific regions or populations would be limited. The results of our study differ from those of previous studies that reported that Asian women with gestational diabetes have a higher risk of developing postpartum T2DM in general $[13,14]$. This finding suggests that it is necessary to assess the incidence risk through population-based studies, considering the differences in specific regions and races.
Fasting glucose level and BMI were identified as the main postpartum risk factors for the incidence of T2DM 1 year after delivery; these may be important for a prevention strategy for T2DM, as they can be monitored and controlled. In this study, the risk of diabetes significantly increased as the fasting glucose level increased, even if the level was below $126 \mathrm{mg} / \mathrm{dL}$, the diagnostic criterion for diabetes. Similarly, in two other prospective studies that followed women with gestational diabetes for 4 and 7 years, respectively, the groups with and without diabetes showed significant differences in fasting glucose at the postpartum baseline, even within the normal range $(100.8 \pm 14.4 \mathrm{mg} / \mathrm{dL}$ vs. $90.0 \pm 9.0 \mathrm{mg} / \mathrm{dL}, P<0.05 ; 97.9 \pm 2.5$ vs. $86.0 \pm 0.9, P<0.05)$ [37,38]. Tura et al. [38] reported that the HR for each SD increase in fasting glucose was 2.99 (95\% CI, 1.96 to 4.57). These findings suggest that the fasting glucose level can be used as an indicator of diabetes risk within the normal range before reaching the diagnostic level. Additionally, we observed that women with both obesity and gestational diabetes had a much higher risk of developing postpartum T2DM, indicating that they require more attention to prevent diabetes. BMI at postpartum was a significant risk factor for postpartum T2DM in this study, and the HR per $1 \mathrm{SD}$ for postpartum BMI was 2.19 (95\% CI, 1.54 to 3.13) in another study [38]. Previous studies reported that pre-pregnancy, pregnancy, and postpartum weight were significant risk factors for postpartum T2DM [26], and Cho et al. [39] reported that postpartum obesity parameters, such as waist circumference, body fat weight, BMI, and weight, significantly increased the risk. Longitudinal studies showed that postpartum weight gain or BMI change increased the risk even further after adjusting for postpartum weight or BMI [40,41]. In a study of 418 Korean women, Moon et al. [40] reported that the incidence of diabetes increased to $8.6 \%, 12.6 \%$, and $16.9 \%(P=0.039)$ along three groups categorized by postpartum BMI change (the lowest tertile [mean $-1.8 \mathrm{~kg} / \mathrm{m}^{2}$ ], the middle tertile [mean -0.2 $\mathrm{kg} / \mathrm{m}^{2}$ ], and the highest tertile [mean $1.6 \mathrm{~kg} / \mathrm{m}^{2}$ ], respectively) [40]. Women in the highest tertile had an approximately 2-fold increase in risk compared to those in the lowest tertile after adjusting for initial postpartum BMI and age [40]. Bao et al. [41] reported through a study with over 18 years of follow-up that there was a $27 \%$ increase in the risk of T2DM for every $5 \mathrm{~kg}$ increase in weight after gestational diabetes (adjusted HR, 1.27; $95 \%$ CI, 1.04 to 1.54). Even the HR was elevated to 43.19 (95\% CI, 13.60 to 137.11) among women who had a $\geq 30 \mathrm{~kg} / \mathrm{m}^{2}$ BMI at baseline and $\geq 5 \mathrm{~kg}$ weight gain after gestational diabetes as compared to women with a $<25 \mathrm{~kg} / \mathrm{m}^{2}$ BMI and $<5 \mathrm{~kg}$ weight gain [41]. Therefore, this evidence suggests that postpartum 
weight management may be an effective prevention strategy that can lower the risk of postpartum T2DM.

This study had issues related to the identification of gestational diabetes and postpartum T2DM subjects. First, it was difficult to confirm the method and diagnostic criteria used for the diagnosis of gestational diabetes because the NHID data do not include oral glucose tolerance test (OGTT) results. Referring to Korean 'Treatment Guidelines for Diabetes' during the study period [42], universal screening at 24 to 28 weeks for gestational diabetes and two-step approach (if over $140 \mathrm{mg} / \mathrm{dL}$ [over 130 $\mathrm{mg} / \mathrm{dL}$ in case of high risk] in $50 \mathrm{~g} \mathrm{OGTT}$, and then $100 \mathrm{~g}$ OGTT) were recommended and diagnostic criteria were changed from the National Diabetes Data Group (NDDG) criteria (100 g OGTT, at least 2 of the following: fasting $\geq 105 \mathrm{mg} /$ dL, 1-hour $\geq 190 \mathrm{mg} / \mathrm{dL}, 2$-hour $\geq 165 \mathrm{mg} / \mathrm{dL}$, and 3-hour $\geq$ $145 \mathrm{mg} / \mathrm{dL}$ ) to the Carpenter-Coustan (C-C) criteria (100 g OGTT, at least 2 of the following: fasting $\geq 95 \mathrm{mg} / \mathrm{dL}$, 1-hour $\geq 180 \mathrm{mg} / \mathrm{dL}, 2$-hour $\geq 155 \mathrm{mg} / \mathrm{dL}$, and 3-hour $\geq 140 \mathrm{mg} / \mathrm{dL}$ ) in the 3rd guideline of 2007. Since the 4th guideline of 2011, one-step approach with the International Association of the Diabetes and Pregnancy Study Group (IADPSG) criteria (75 g OGTT, at least 1 of the following: fasting $\geq 92 \mathrm{mg} / \mathrm{dL}$, 1-hour $\geq 180 \mathrm{mg} / \mathrm{dL}$, and 2-hour $\geq 153 \mathrm{mg} / \mathrm{dL}$ ) was also recommended in addition to a previous two-step approach. The prevalence of gestational diabetes is affected by the applied diagnostic criteria. The prevalence of gestational diabetes increased by $50 \%$ to $60 \%$ when the C-C criteria were applied instead of the NDDG criteria $[43,44]$, and it was twice as high when the one-step approach with IADPSG criteria was applied compared to the twostep approach with the C-C criteria [45]. Therefore, it is necessary to consider applied diagnostic criteria and their impacts on the prevalence of gestational diabetes and further incidence of postpartum T2DM. To consider the impact of changes of diagnostic criteria over time and multiple recommended criteria, our study compared the incidence risk by matching subjects with the same year of delivery. Nonetheless, careful interpretation of our results is needed due to the lack of information on applied criteria to each subject for the diagnosis of gestational diabetes. Second, verification of T2DM by diagnosis or drug codes may be different from the real incidence. Studies for validation of identification of diabetes using diagnosis codes showed that the sensitivity and specificity changed according to the operational definition [46,47]. More complex criteria for the identification of diabetes than more simplified ones were related to relatively lower sensitivity and higher specificity [46,47]. The level of sensitivity and specificity could affect the incidence estimation: low sensitivity leads to underestimation through false negatives, and low specificity leads to overestimation through false positives. Thus, an appropriate condition of an operational definition is required in consideration of the sensitivity and specificity of the tradeoff relationship. Identification of diabetes through two or more relevant diabetes ICD codes, as one criterion in this study, showed fair validity (sensitivity $88.4 \%$ to $92.3 \%$, specificity $96.9 \%$ to $99 \%$, positive predictive value [PPV] $77.2 \%$ to 94\%) [47-49]. Lipscombe et al. [47] recommended diagnosis code 'AND' drug/fee code combination ("one hospitalization or physician claim for diabetes AND either one prescription for an anti-diabetic medication or one physician claim with a diabetesspecific fee code" [sensitivity $84.2 \%$, specificity $99.2 \%$, PPV $92.5 \%]$ ) as the best definition than diagnosis code 'OR' drug code combination ("one hospitalization or 2 physician claims for diabetes OR one prescription for an anti-diabetic medication within 2 years" [sensitivity 90.7\%, specificity 97.5\%, PPV $98.9 \%]$ ). Although there may be concerns about the possibility of overestimation due to the 'OR' combination used in this study, it is assumed that overestimation was not serious enough to concern because the incidence rate in our study was lower than that of the clinical studies and similar to that of other population-based studies [10].

This study minimized the effects of recruitment bias and drop-outs during follow-up and long-term follow-up by using a large-scale nationally representative sample of female subjects. Additionally, this study tried to overcome the limitations of heterogeneous or unconfirmed regions or races observed in other studies by using homogenous Korean national data (above 95\% estimated as Korean). Moreover, subjects with pregestational diabetes were strictly excluded by confirming that there was no diagnosis of diabetes before inclusion in the study (using data until index pregnancy since 2002, which ranged from 1 to 13 years depending on the subject's inclusion date). The control group was established by matching the gestational diabetes group. The effects of confounding variables were adjusted to accurately assess the risk of postpartum T2DM. Furthermore, comprehensive factors were included in the assessment of risk factors during the postpartum period to help develop strategies that can prevent postpartum T2DM.

There were some limitations to this study. As a retrospective cohort study, we could not preplan subjects' identification and data measurements and had limited control of them [50]. First, there are concerns about accuracy and validity in the identification of subjects through diagnosis or drug codes in the NHID. For example, there may be inaccuracy while entering the diag- 
nosis code, and the medication may be prescribed for purposes other than for diabetes treatment. For these reasons, in this study, postpartum diabetes was defined based on diagnosis codes that were entered twice over different treatment days. For the hypoglycemic agent metformin, considering the possibility that it could be used for other purposes, postpartum diabetes was only defined when the drug and the diabetes diagnosis codes existed together. However, discrepancies between recorded codes and actual subjects' medical diagnoses could still exist. Second, due to the incompleteness of existing data, there is a limit to the availability of important variables. For example, clinical information on disease severity such as OGTT values at diagnosis, treatment and control of glucose levels during pregnancy, and recurrence of gestational diabetes was not available. Moreover, hemoglobin A1c (HbA1c) of $6.5 \%$ (48 mmol/mol) or higher may be used to diagnose diabetes [32,33]; however, HbAlc was not one of the health screening items of the NHID and could not be used in our study.

This population-based cohort study assessed the risk and risk factors for postpartum T2DM in women with gestational diabetes. The findings of this study may be used to increase the risk awareness of subjects and provide motivation for prevention actions by notifying the subjects with more accurate individualized risks. Additionally, results of health examinations may also be used to identify groups with a high risk of diabetes in clinical settings and increase the likelihood of active intervention or early diagnosis.

\section{CONFLICTS OF INTEREST}

No potential conflict of interest relevant to this article was reported.

\section{ACKNOWLEDGMENTS}

This study used the National Health Insurance Service-National Health Information Database-customized data (NHIS-2019-1044) of the National Health Insurance Service. This study was funded by Chodang University (Planning and Research Department-489 2018.09.13).

This study is an excerpt from the doctoral dissertation of $\mathrm{Mi}$ Jin Choi at Seoul National University (https://s-space.snu.ac.kr/ bitstream/10371/161860/1/000000157918.pdf). This study was presented at the 54th Online Fall Conference of the Korean Society of Women Health Nursing, November 27, 2020.

The authors give special thanks to the doctoral dissertation committee (Prof. Hae Won Kim, Smi Choi, and Iksoo Huh, College of Nursing, Seoul National University; Prof. Somi Park, Department of Nursing, Wonju College of Medicine, Yonsei University) for their warm reviews and comments.

\section{AUTHOR CONTRIBUTIONS}

Conception or design: M.J.C. Acquisition, analysis, or interpretation of data: M.J.C., J.C., C.W.C. Drafting the work or revising: M.J.C., J.C., C.W.C. Final approval of the manuscript: M.J.C., J.C., C.W.C.

\section{ORCID}

Mi Jin Choi https://orcid.org/0000-0003-4379-2733

Jimi Choi https://orcid.org/0000-0003-2834-2718

\section{REFERENCES}

1. Li Z, Cheng Y, Wang D, Chen H, Chen H, Ming WK, et al. Incidence rate of type 2 diabetes mellitus after gestational diabetes mellitus: a systematic review and meta-analysis of 170,139 women. J Diabetes Res 2020;2020:3076463.

2. Song C, Lyu Y, Li C, Liu P, Li J, Ma RC, et al. Long-term risk of diabetes in women at varying durations after gestational diabetes: a systematic review and meta-analysis with more than 2 million women. Obes Rev 2018;19:421-9.

3. Bellamy L, Casas JP, Hingorani AD, Williams D. Type 2 diabetes mellitus after gestational diabetes: a systematic review and meta-analysis. Lancet 2009;373:1773-9.

4. Yoon KH, Lee JH, Kim JW, Cho JH, Choi YH, Ko SH, et al. Epidemic obesity and type 2 diabetes in Asia. Lancet 2006;368:1681-8.

5. Torloni MR, Betran AP, Horta BL, Nakamura MU, Atallah $\mathrm{AN}$, Moron AF, et al. Prepregnancy BMI and the risk of gestational diabetes: a systematic review of the literature with meta-analysis. Obes Rev 2009;10:194-203.

6. International Diabetes Federation. IDF diabetes atlas. 9th ed. Brussels: International Diabetes Federation; 2019. p. 3261.

7. Rhee EJ. Diabetes in Asians. Endocrinol Metab (Seoul) 2015;30:263-9.

8. Song SO, Song YD, Kim DU, Nam JY, Park KH, Lee YH, et al. A study on the prevalence and characteristics of diabetes in the past 10 years using data from the National Health Insurance Service (Research Report 2014-20-009). Goy- 
ang: National Health Insurance Service Ilsan Hospital; 2014. p. 23-58 [cited 2022 Feb 2]. Available from: https:// www.nhimc.or.kr/cntFileDownLoad.do?DownLoadDir=/ down_data/audit/\&FileName $=$ audit05_etc08.pdf.

9. Song SH, Hardisty CA. Early onset type 2 diabetes mellitus: a harbinger for complications in later years: clinical observation from a secondary care cohort. QJM 2009;102:799806.

10. Feig DS, Zinman B, Wang X, Hux JE. Risk of development of diabetes mellitus after diagnosis of gestational diabetes. CMAJ 2008;179:229-34.

11. Jang HC. Gestational diabetes in Korea: incidence and risk factors of diabetes in women with previous gestational diabetes. Diabetes Metab J 2011;35:1-7.

12. Kim C, Newton KM, Knopp RH. Gestational diabetes and the incidence of type 2 diabetes: a systematic review. Diabetes Care 2002;25:1862-8.

13. Girgis CM, Gunton JE, Cheung NW. The influence of ethnicity on the development of type 2 diabetes mellitus in women with gestational diabetes: a prospective study and review of the literature. ISRN Endocrinol 2012;2012: 341638.

14. Jenum AK, Morkrid K, Sletner L, Vangen S, Torper JL, Nakstad B, et al. Impact of ethnicity on gestational diabetes identified with the WHO and the modified International Association of Diabetes and Pregnancy Study Groups criteria: a population-based cohort study. Eur J Endocrinol 2012;166: 317-24.

15. Kwak SH, Choi SH, Jung HS, Cho YM, Lim S, Cho NH, et al. Clinical and genetic risk factors for type 2 diabetes at early or late post partum after gestational diabetes mellitus. J Clin Endocrinol Metab 2013;98:E744-52.

16. Lee H, Jang HC, Park HK, Metzger BE, Cho NH. Prevalence of type 2 diabetes among women with a previous history of gestational diabetes mellitus. Diabetes Res Clin Pract 2008;81:124-9.

17. American Diabetes Association. Standards of medical care in diabetes: 2015 abridged for primary care providers. Clin Diabetes 2015;33:97-111.

18. Hod M, Kapur A, Sacks DA, Hadar E, Agarwal M, Di Renzo GC, et al. The International Federation of Gynecology and Obstetrics (FIGO) initiative on gestational diabetes mellitus: a pragmatic guide for diagnosis, management, and care. Int J Gynaecol Obstet 2015;131 Suppl 3:S173-211.

19. Aroda VR, Christophi CA, Edelstein SL, Zhang P, Herman WH, Barrett-Connor E, et al. The effect of lifestyle interven- tion and metformin on preventing or delaying diabetes among women with and without gestational diabetes: the Diabetes Prevention Program outcomes study 10-year follow-up. J Clin Endocrinol Metab 2015;100:1646-53.

20. Nielsen KK, Kapur A, Damm P, de Courten M, Bygbjerg IC. From screening to postpartum follow-up: the determinants and barriers for gestational diabetes mellitus (GDM) services, a systematic review. BMC Pregnancy Childbirth 2014;14:41.

21. Kim C, McEwen LN, Piette JD, Goewey J, Ferrara A, Walker EA. Risk perception for diabetes among women with histories of gestational diabetes mellitus. Diabetes Care 2007; 30:2281-6.

22. Rayanagoudar G, Hashi AA, Zamora J, Khan KS, Hitman GA, Thangaratinam S. Quantification of the type 2 diabetes risk in women with gestational diabetes: a systematic review and meta-analysis of 95,750 women. Diabetologia 2016;59: 1403-11.

23. Cheung NW, Helmink D. Gestational diabetes: the significance of persistent fasting hyperglycemia for the subsequent development of diabetes mellitus. J Diabetes Complications 2006;20:21-5.

24. Shin NR, Yoon SY, Cho GJ, Choi SJ, Kwon HS, Hong SC, et al. A Korean multicenter study of prenatal risk factors for overt diabetes during the postpartum period after gestational diabetes mellitus. Int J Gynaecol Obstet 2016;132:342-6.

25. Kim SJ, Chun H, Jang EH, Lee JS, Kim M, Baek KH, et al. Risk factors for progression to postpartum diabetes mellitus and perinatal complications in women with gestational diabetes mellitus. J Korean Diabetes 2014;15:116-23.

26. Baptiste-Roberts K, Barone BB, Gary TL, Golden SH, Wilson LM, Bass EB, et al. Risk factors for type 2 diabetes among women with gestational diabetes: a systematic review. Am J Med 2009;122:207-14.

27. Bengtson AM, Ramos SZ, Savitz DA, Werner EF. Risk factors for progression from gestational diabetes to postpartum type 2 diabetes: a review. Clin Obstet Gynecol 2021;64:23443.

28. National Health Insurance Service. Health insurance coverage and population [Internet]. Wonju: National Health Insurance Service; 2020 [cited 2022 Feb 2]. Available from https://www.nhis.or.kr/nhis/policy/wbhada01700m01.do.

29. Kim S, Kim MS, You SH, Jung SY. Conducting and reporting a clinical research using Korean healthcare claims database. Korean J Fam Med 2020;41:146-52.

30. Seong SC, Kim YY, Khang YH, Park JH, Kang HJ, Lee H, 
et al. Data resource profile: the national health information database of the National Health Insurance Service in South Korea. Int J Epidemiol 2017;46:799-800.

31. Damm P, Houshmand-Oeregaard A, Kelstrup L, Lauenborg J, Mathiesen ER, Clausen TD. Gestational diabetes mellitus and long-term consequences for mother and offspring: a view from Denmark. Diabetologia 2016;59:1396-9.

32. Korean Diabetes Association. 2015 Treatment guidelines for diabetes [Internet]. Seoul: Korean Diabetes Association; 2015 [cited 2022 Feb 2]. Available from: https://www.diabetes. or.kr/pro/publish/guide.php? code $=$ guide $\&$ year_v $=2015 \&$ number $=638 \&$ mode $=$ view .

33. Korean Diabetes Association. Diabetes fact sheet in Korea 2018 [Internet]. Seoul: Korean Diabetes Association; 2018 [cited 2022 Feb 2]. Available from: https://www.diabetes. or.kr/pro/news/admin.php? category $=$ A\&code $=$ admin $\&$ mo $\mathrm{de}=$ view\&number $=1615$.

34. Cho GJ, Park JH, Lee H, Yoo S, Shin SA, Oh MJ. Prepregnancy factors as determinants of the development of diabetes mellitus after first pregnancy. J Clin Endocrinol Metab 2016;101:2923-30.

35. Jang HC, Yim CH, Han KO, Yoon HK, Han IK, Kim MY, et al. Gestational diabetes mellitus in Korea: prevalence and prediction of glucose intolerance at early postpartum. Diabetes Res Clin Pract 2003;61:117-24.

36. Kim YL, Cho YW, Park SW, Lee SK, Ahn IS, Na BW, et al. Antepartum characteristics predicting persistent postpartum glucose intolerance in the patients with gestational diabetes mellitus (GDM). J Korean Diabetes Assoc 2000;24:46-59.

37. Cho NH, Lim S, Jang HC, Park HK, Metzger BE. Elevated homocysteine as a risk factor for the development of diabetes in women with a previous history of gestational diabetes mellitus: a 4-year prospective study. Diabetes Care 2005;28: 2750-5.

38. Tura A, Grassi A, Winhofer Y, Guolo A, Pacini G, Mari A, et al. Progression to type 2 diabetes in women with former gestational diabetes: time trajectories of metabolic parameters. PLoS One 2012; 7:e50419.

39. Cho NH, Jang HC, Park HK, Cho YW. Waist circumference is the key risk factor for diabetes in Korean women with history of gestational diabetes. Diabetes Res Clin Pract 2006; 71:177-83.

40. Moon JH, Kwak SH, Jung HS, Choi SH, Lim S, Cho YM, et al. Weight gain and progression to type 2 diabetes in women with a history of gestational diabetes mellitus. J Clin Endocrinol Metab 2015;100:3548-55.

41. Bao W, Yeung E, Tobias DK, Hu FB, Vaag AA, Chavarro $\mathrm{JE}$, et al. Long-term risk of type 2 diabetes mellitus in relation to BMI and weight change among women with a history of gestational diabetes mellitus: a prospective cohort study. Diabetologia 2015;58:1212-9.

42. Korean Diabetes Association. 2007 Treatment guidelines for diabetes. 3th ed. Seoul: Korean Diabetes Association; 2007. p. 14-16, 144-148.

43. Jang HC, Cho YM, Park KS, Kim SY, Lee HK, Kim MY, et al. Pregnancy outcome in Korean women with gestational diabetes mellitus diagnosed by the Carpenter-Coustan criteria. J Korean Diabetes Assoc 2004;28:122-30.

44. Ferrara A, Hedderson MM, Quesenberry CP, Selby JV. Prevalence of gestational diabetes mellitus detected by the National Diabetes Data Group or the carpenter and coustan plasma glucose thresholds. Diabetes Care 2002;25:1625-30.

45. Kim MH, Kwak SH, Kim SH, Hong JS, Chung HR, Choi $\mathrm{SH}$, et al. Pregnancy outcomes of women additionally diagnosed as gestational diabetes by the International Association of the Diabetes and Pregnancy Study Groups Criteria. Diabetes Metab J 2019;43:766-75.

46. Khokhar B, Jette N, Metcalfe A, Cunningham CT, Quan H, Kaplan GG, et al. Systematic review of validated case definitions for diabetes in ICD-9-coded and ICD-10-coded data in adult populations. BMJ Open 2016;6:e009952.

47. Lipscombe LL, Hwee J, Webster L, Shah BR, Booth GL, Tu $\mathrm{K}$. Identifying diabetes cases from administrative data: a population-based validation study. BMC Health Serv Res 2018;18:316.

48. O’Connor PJ, Rush WA, Pronk NP, Cherney LM. Identifying diabetes mellitus or heart disease among health maintenance organization members: sensitivity, specificity, predictive value, and cost of survey and database methods. Am J Manag Care 1998;4:335-42.

49. Chen G, Khan N, Walker R, Quan H. Validating ICD coding algorithms for diabetes mellitus from administrative data. Diabetes Res Clin Pract 2010;89:189-95.

50. Hulley S, Cummings S, Browner W, Grady D, Newman T. Designing clinical research. 4th ed. Philadelphia: Lippincott Williams \& Wilkins; 2013. Chapter 9, Enhancing causal inference in observational studies; p. 117-36. 